\title{
Pyogenic Granuloma of the Duodenum Treated Successfully by Endoscopic Mucosal Resection
}

Seon-Young Park, Chang-Hwan Park, Wan-Sik Lee, Hyun-Soo Kim, Sung-Kyu Choi, and Jong-Sun Rew

Department of Internal Medicine, Chonnam National University Medical School, Gwangju, Korea

Pyogenic granuloma is a lobular capillary hemangioma that occurs mostly on the skin and the mucosal surfaces of the oral cavity and tongue. Only a few cases in other parts of the digestive tract have been reported. Gastrointestinal pyogenic granuloma is a rare cause of hemorrhage in the digestive tract, but should be considered in the differential diagnosis of patients with gastrointestinal bleeding. We report the case of a 62-year-old anemic woman found to have a pyogenic granuloma of the duodenum, which was treated adequately by endoscopic mucosal resection. (Gut and Liver 2009;3:48-51)

Key Words: Granuloma; Pyogenic; Duodenum

\section{INTRODUCTION}

Pyogenic granuloma is a lobular capillary hemangioma that presents as a polypoid red mass. The lesion is found on the skin, particularly the lips, face and fingers, and furthermore, on the mucosal surface of the oral cavity and tongue. ${ }^{1}$ Pyogenic granuloma may also occur in the gastrointestinal tract although it is quite rare. Here, we report a case of pyogenic granuloma of the duodenum in 62-year-old woman with anemia, which was successfully treated by endoscopic mucosal resection. We also present a literature review of the clinical features and management of pyogenic granuloma.

\section{CASE REPORT}

A 62-year-old woman presented with anemia of unknown origin. Laboratory findings was as follows: WBC

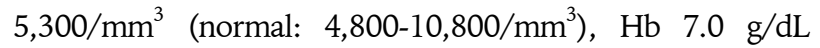

(12-18 g/dL), hematocrit $23.7 \%$ (37-52\%), platelet $370 \times$ $10^{3} / \mathrm{mm}^{3}\left(130-450 \times 10^{3} / \mathrm{mm}^{3}\right)$, serum iron $5 \mu \mathrm{g} / \mathrm{dL}(65-$ $157 \mu \mathrm{g} / \mathrm{dL})$, TIBC $385 \mu \mathrm{g} / \mathrm{dL}(256-426 \mu \mathrm{g} / \mathrm{dL})$, serum ferritin $7.11 \mathrm{ng} / \mathrm{mL}(6.9-323 \mathrm{ng} / \mathrm{mL})$. Upper endoscopy revealed a 10-mm-diameter strawberry-like semipedunculated lesion in the second portion of the duodenum (Fig. 1). Abdominal CT showed $0.6 \mathrm{~cm}$ nodular strong enhancing lesion in the second portion of the duodenum (Fig. 2). Colonoscopy revealed no abnormal finding. Fecal occult blood test was positive indicating occult gastrointestinal blood loss. Because the lesion was considered to be the cause of iron deficiency anemia, it required resection in order to prevent worsening anemia. So, we per-

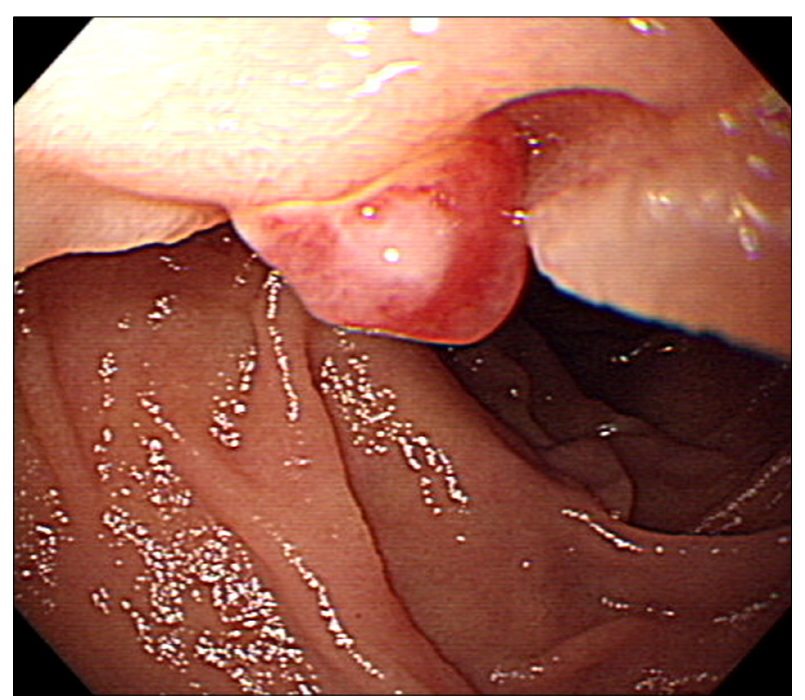

Fig. 1. Upper-duodenum endoscopic findings. A 10-mm-diameter semipedunculated strawberry-like lesion with a whitish exudate evident in the second portion of the duodenum.

Correspondence to: Chang-Hwan Park

Department of Internal Medicine, Chonnam National University Medical School, 8, Hak-dong, Dong-gu, Gwangju 501-757, Korea

Tel: +82-62-220-6296, Fax: +82-62-228-1330, E-mail: p1052ccy@hanmail.net

Received on March 16, 2008. Accepted on September 5, 2008. 
formed endoscopic mucosal resection (EMR) of the lesion (Fig. 3). There were no complications during or after resection including massive bleeding or perforation. Histological examination of the resected specimen demon-

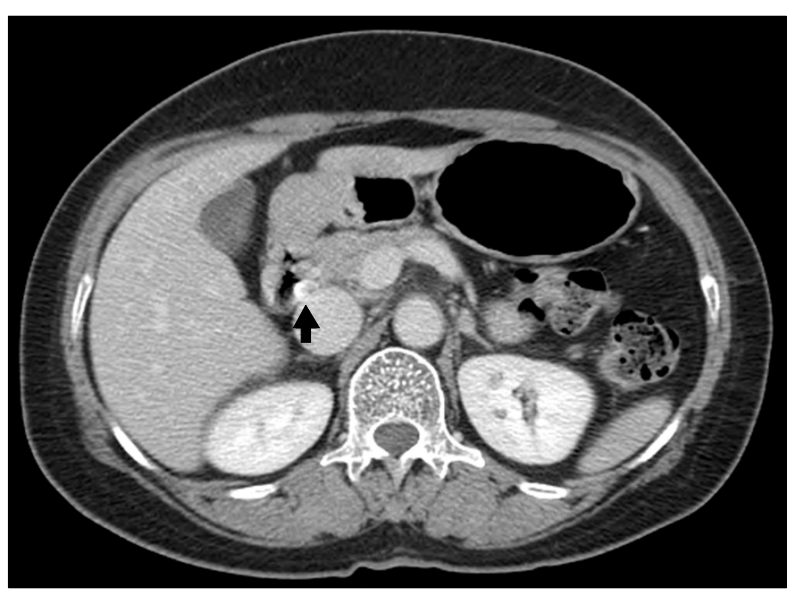

Fig. 2. Contrast-enhanced abdominal computed tomography showing a 10-mm-diameter strongly enhanced lesion (arrow) in the second portion of the duodenum. strated a polypoid lesion containing numerous capillaries of variable sizes. There was intraluminal growth, ulcerated mucosa, a surrounding nonspecific inflammatory infiltrate, and overlying eosinophilic necrotic material. The histological features were consistent with those of a pyogenic granuloma (Fig. 4). The patient was discharged 4 days after EMR. Fourteen months later, she was asymptomatic, and there was no evidence of complication or tumor recurrence.

\section{DISCUSSION}

Pyogenic granuloma was first reported by Hartzell in 1904. ${ }^{2}$ To our knowledge, 35 cases of gastrointestinal pyogenic granuloma have been reported (Table 1). The locations of pyogenic granuloma were as follows: 14 in the esophagus, ${ }^{3-10} 2$ in the stomach, ${ }^{10,11} 1$ in the duodenum, ${ }^{12}$ 1 in the jejunum, ${ }^{13} 7$ in the ileum, ${ }^{7,10,13-15}$ and 10 in the colon. ${ }^{10,13,16-19}$ Pyogenic granulomas range in color from dark red to fresh sanguine. Although the surface is usually smooth, it tends to be friable, hemorrhagic, and accompanied by erosion and ulcers, and it sometimes ex-
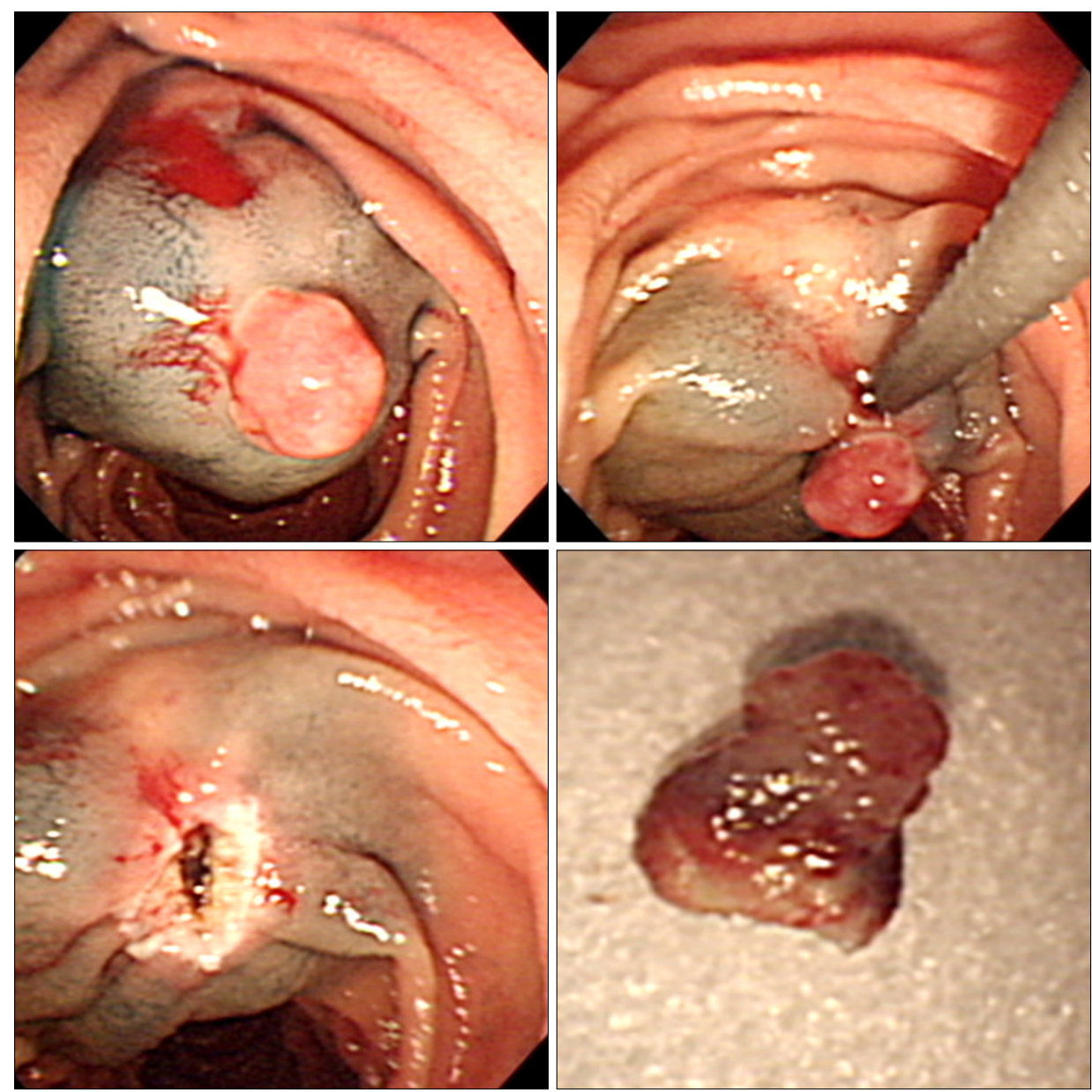

Fig. 3. Endoscopic mucosal resection (EMR). A 10-mm-diameter semipedunculated strawberry-like lesion in the second portion of the duodenum was removed by EMR (injection and snaring method). 

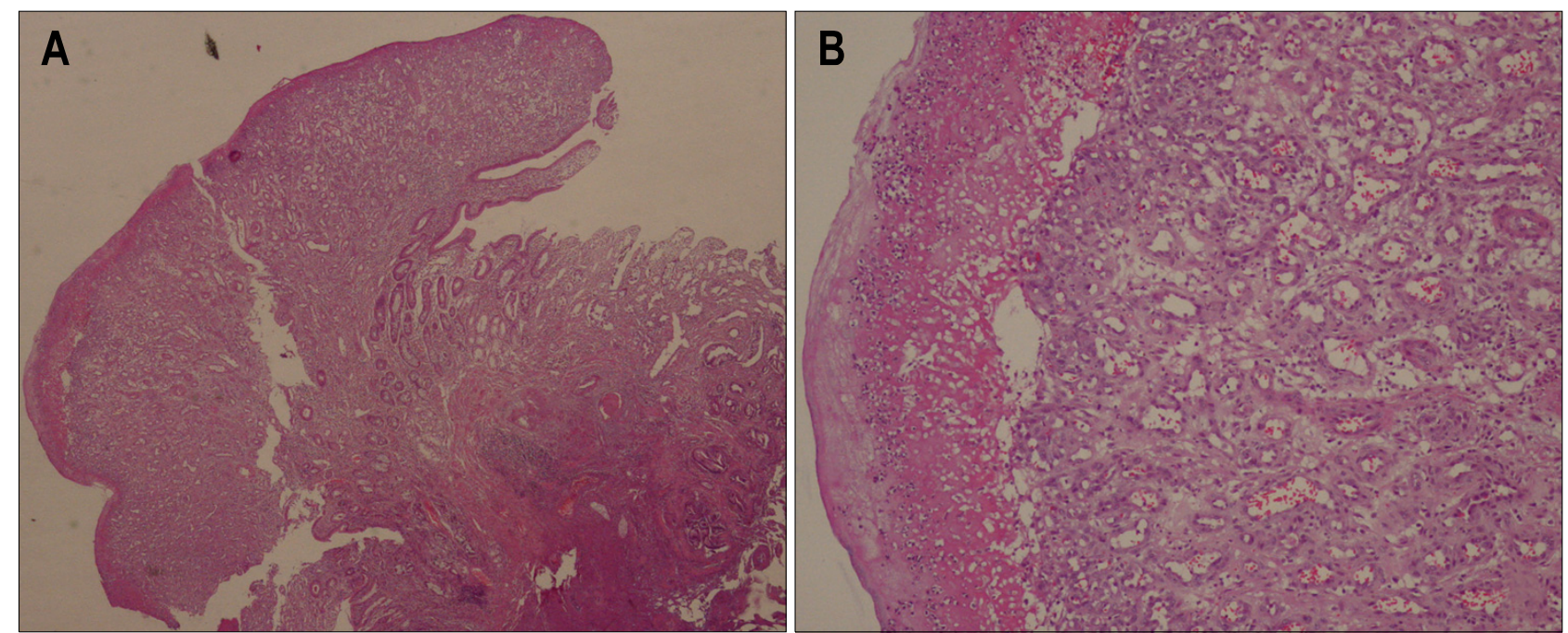

Fig. 4. Photomicrograph showing the features of pyogenic granuloma: the polypoid mass shows edematous granulation tissue with proliferation of dilated capillaries and infiltration of inflammatory cells with erosion (A, H\&E stain, original magnification $\times 20$; B, H\&E stain, original magnification $\times 100)$.

Table 1. Clinical Characteristics of Gastrointestinal Pyogenic Granuloma Reported in the Literature

\begin{tabular}{lc}
\hline \multicolumn{1}{c}{ No. of cases } & 35 \\
\hline Sex (M:F) & $16: 19$ \\
Age (years) & 1.5-82 (mean, 50.7) \\
Size & $3-30 \mathrm{~mm}$ \\
Clinical symptoms & \\
Subclinical symptoms & 5 \\
Melena or tarry stool & 17 \\
Anemia & 2 \\
Discomfort on swallowing & 4 \\
Substernal or epigastric discomfort & 6 \\
Lower abdominal discomfort & 1 \\
Location & 14 \\
Esophagus & 2 \\
Stomach & 1 \\
Duodenum & 1 \\
Jejunum & 7 \\
Ileum & 10 \\
Colon & \\
Shape & 8 \\
Pedunculated & 19 \\
Semipedunculated & 6 \\
Sessile & \\
Treatment & 2 \\
Removal by biopsy & 8 \\
ESP or EMR & 3 \\
Surgical resection & 1 \\
Endoscopic ablation & \\
No treatment & \\
\hline
\end{tabular}

ESP, endoscopic snare polypectomy; EMR, endoscopic mucosal resection. ibits pyogenic exudates. ${ }^{20,21}$ In 30 tumors removed by surgical or endoscopic method, there was no recurrence at follow-up. Recurrence was seen in 2 cases where the tumor was removed by biopsy. ${ }^{4,16}$ Our patient has exhibited no tumor recurrence after 14 months of follow-up.

Although infection, mechanical irritation, and hormones have been proposed as etiologic factors for pyogenic granuloma, there is still controversy regarding the mechanisms underlying the development of this tumor. ${ }^{20}$ Gastrointestinal pyogenic granuloma are benign lesions that are considered reactive (e.g., as the result of minor trau$\mathrm{ma})$. Therefore, resection is often required, as their hypervascular nature predisposes them to hemorrhage. ${ }^{11,13-15,22}$ No post-resection bleeding or perforation have been reported for 16 cases with endosopic snare polypectomy or EMR. So, endosopic snare polypectomy or EMR is relatively safe, if available. In our patient, the lesion was considered to be the cause of iron deficiency anemia, it required resection in order to prevent worsening anemia. So, we performed EMR of the lesion with no complications.

In summary, we report a case of patient with pyogenic granuloma of the duodenum, which was safely removed by EMR and did not recur on long term follow-up. Further study of gastrointestinal pyogenic granuloma is necessary to better understanding of the clinical and pathological characteristics of the lesion.

\section{REFERENCES}

1. Enzinger FM, Weiss SW. Benign tumors and tumor-like le- 
sions of blood vessels. In: Soft tissue tumors. 4 th ed. St. Louis: Mosby, 2001:864-865.

2. Hartzell MB. Granuloma pyogenicus. J Cutan Dis 1904; 22:520-523.

3. Noh KA, Moom JS, Kim KS, Kim CD, Ryu HS, Hyun JH. A case of pyogenic granuloma of esophagus. Korean J Gastroenterol 1989;21:653-657.

4. Okumura T, Tanoue S, Chiba K, Tanaka S. Lobular capillary hemangioma of the esophagus. A case report and review of the literature. Acta Pathol Jpn 1983;33:1303-1308.

5. Craig RM, Carlson S, Nordbrock HA, Yokoo H. Pyogenic granuloma in Barrett's esophagus mimicking esophageal carcinoma. Gastroenterology 1995;108:1894-1896.

6. Okada N, Matsumoto T, Kurahara K, et al. Pyogenic granuloma of the esophagus treated by endoscopic removal. Endoscopy 2003;35:375.

7. van Eeden S, Offerhaus GJ, Morsink FH, van Rees BP, Busch OR, van Noesel CJ. Pyogenic granuloma: an unrecognized cause of gastrointestinal bleeding. Virchows Arch 2004;444:590-593.

8. Han CH, Kim YS, Cho YK, et al. Two cases of esophageal pyogenic granuloma treated by endoscopic mucosal resection. Korean J Gastrointest Endosc 2005;30:75-79.

9. Manabe $\mathrm{T}$, Goto $\mathrm{H}$, Enya $\mathrm{M}$, et al. A case of pyogenic granuloma in the cervical esophagus. Nippon Shokakibyo Gakkai Zasshi 1998;95:230-232.

10. Morita T, Tamura S, Okawauchi K, et al. A case of pyogenic granuloma in the sigmoid colon treated with argon plasma coagulation. Dig Endosc 2005;17:253-256.

11. Kusakabe A, Kato H, Hayashi K, et al. Pyogenic granuloma of the stomach successfully treated by endoscopic resection after transarterial embolization of the feeding artery. J Gastroenterol 2005;40:530-535.

12. Hirakawa K, Aoyagi K, Yao T, Hizawa K, Kido H, Fujishima $\mathrm{M}$. A case of pyogenic granuloma in the duodenum: successful treatment by endoscopic snare polypectomy. Gastrointest Endosc 1998;47:538-540.

13. Yao T, Nagai E, Utsunomiya $T$, Tsuneyoshi $M$. An intestinal counterpart of pyogenic granuloma of the skin. A newly proposed entity. Am J Surg Pathol 1995;19:10541060.

14. Iwakubo A, Tsuda T, Kubota M, Wakabayashi J, Kobayashi K, Morita K. Diagnostic 99mTc-labeled red blood cells scintigraphy in gastrointestinal tract bleeding from an intestinal pyogenic granuloma. Kaku Igaku 1989;26:14391443.

15. Hizawa $K$, Iida $M$, Matsumoto $T$, Kohrogi $N$, Yao $T$, Fujishima M. Neoplastic transformation arising in PeutzJeghers polyposis. Dis Colon Rectum 1993;36:953-957.

16. Kim SW, Kim HY, Jung HJ, Paik SW, Kim EJ, Yoon SO. A case of recurrent pyogenic granuloma of the rectum. Korean J Med 1991;41:135-139.

17. Chen TC, Lien JM, Ng KF, Lin CJ, Ho YP, Chen CM. Multiple pyogenic granulomas in sigmoid colon. Gastrointest Endosc 1999;49:257-259.

18. Blanchard SS, Chelimsky G, Czinn SJ, Redline R, Splawski J. Pyogenic granuloma of the colon in children. J Pediatr Gastroenterol Nutr 2006;43:119-121.

19. Carmen Gonzalez-Vela M, Fernando Val-Bernal J, Francisca Garijo M, Garcia-Suarez C. Pyogenic granuloma of the sigmoid colon. Ann Diagn Pathol 2005;9:106-109.

20. Bhaskar SN, Jacoway JR. Pyogenic granuloma--clinical features, incidence, histology, and result of treatment: report of 242 cases. J Oral Surg 1966;24:391-398.

21. Serban DE, Florescu P. Colonic pyogenic granuloma in children: a rare or rarely recognized entity. Am J Gastroenterol 2003;98:2106-2107.

22. Iwasaka C, Yazu T, Suehiro A, et al. A case of pyogenic granuloma in the sigmoid colon. Nippon Shokakibyo Gakkai Zasshi 1995;92:885-888. 